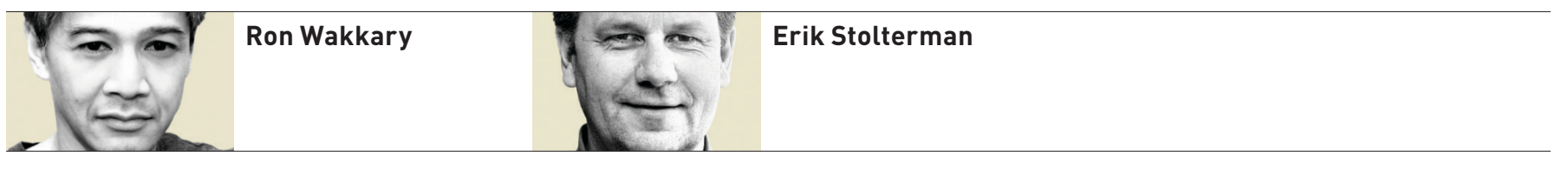

\title{
Time to Move On
}

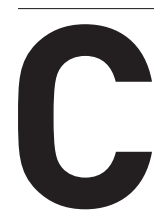
ontemporary technology is changing our everyday environments. $\mathrm{HCI}$ is no longer only about the individual working in isolation with a computer at a desk. Our homes, workplaces, and public spaces are becoming interactive. Still, it seems as if the "power" to be part of the design of this new world is primarily left to professionals. In this issue's cover story, Christopher Le Dantec argues for a move toward what he calls social design. He writes, "Social design is meant to evoke a ... set of actions we take through the creation of computing systems and interfaces that are meant to empower, support, and act as resources for individuals and groups for whom such things might not normally be available" and that "social design focuses on the kinds of problems whose solutions require human relation and collective action." He shows by a number of examples and by theorizing the notion of social design that it is not only needed but also readily possible. Even though social design has always been "an important current within the field since its inception,” Le Dantec ends his cover story by stating that we need an "evolution toward identifying and designing for collective encounters with the social and cultural and political contours of life.”
In this issue we also have a Special Topic that portrays a growing research community of diverse backgrounds but shared interests in the convergence of craft, computation, fabrication, and play. Our guest editors Joshua Tanenbaum and Gillian Smith bring together researchers who investigate these intersections in wearable and embodied interactions for games, design fictions and futures, and making and crafting as intervention, critique, and subversion.

This issue is our last as editors-inchief. It has been an amazing six years in which we have had the honor of engaging and sharing the richness of HCI and interaction design research and practice. We aimed to mirror and support our diverse HCI communities and in the process have gained many new colleagues and have learned so much. In an enterprise like Interactions, a great number of people have been involved and without them the magazine would not be possible! First we want to thank our incredible assistants who helped us every step of the way, Audrey Desjardins, who began in 2012 and became the editor for Demo Hour, How Was It Made?, Blog@ IX (online and in-print), and coordinated our social media. And before her, Leah Maestri, who started in 2010 and was also editor of Demo Hour.

We also want to thank Executive Editor Diane Crawford, Managing
Editors John Stanik and Denise Doig, and Director of Publications Scott Delman, all from ACM. Together these folks and others unfailingly supported the day-to-day necessities of Interactions along with our ideas for change, no matter how small or large. We are also grateful for the expertise of Andrij Borys and his team at Andrij Borys Associates, who with every issue brought immense design talent that transformed the content into a beautiful magazine. And we thank the SIGCHI Executive Committee and the ACM Publications Board for their support throughout the years.

Last but certainly not least, we owe an incalculable debt of gratitude to all of the contributors of the past six years (way too many to count!) and most of all to our forum editors and columnists, who with each issue co-shaped the magazine with timely, insightful, and brilliant contributions.

These years working with

Interactions have been exciting and rewarding, but now it is time to pass on the magazine to the new editorsin-chief, Gilbert Cockton and Simone Barbosa. We wish them and the magazine well. We are proud of what we all did together and look forward to continuing as avid readers and fans of Interactions.

Ron Wakkary and Erik Stolterman

\section{This issue is our last as editors-in-chief. It has been an amazing six years in which we have had the honor of engaging and sharing the richness of $\mathrm{HCl}$ and interaction design research and practice.}

